\title{
Time to Stop Helicobacter pylori, no Matter by Antibiotic, Probiotic or Vaccine
}

\author{
Amin Talebi Bezmin \\ Department of Bacteriology, Faculty of Medical Sciences, Tarbiat Modares University, P.O. Box14115-111, Tehran, Iran. \\ amin.talebi@modares.ac.ir
}

Received: 2 May 2016, Accepted: 18 Jun 2016

Please cite this article as: Talebi Bezmin A. Time to Stop Helicobacter pylori, no Matter by Antibiotic, Probiotic or Vaccine. Res Mol Med. 2016; 4 (3): 1-2

Helicobacter pylori $(H$. pylori) is a transmissible bacterium of the gastric mucosal surface that induce progressive damage in gastric epithelial cells (1). Since the historic report of the culture of spiral organisms and its characterization by the Barry Marshall and Robin Warren in 1984, it is known that more than $50 \%$ of world's population is infected with this microaerophilic organism $(2,3)$. In 1994, the International Agency for Research on Cancer (IARC) declared $H$. pylori to be a group I human carcinogen for gastric adenocarcinoma (4). The second subsequent event in same year was that the national Institutes of Health (NIH) recognized that most recurrent duodenal and gastric ulcers were caused by $H$. pylori and thus chemotherapy was highly recommended (4). Thereafter, microbiologists and gastroenterologists decided to intensively focus on eradicating $H$. pylori infection (5). In this paper, I provide novel conclusive and straight data related to the management of $H$. pylori infection according to the policy for eradicating the infection (6). Moreover, an actual picture drawn by new paradigm against the $H$. pylori is clearly discussed with emphasis on therapy (7).

1- Standard triple therapy (standard dose proton pump inhibitor, amoxicillin $1 \mathrm{~g}$, and clarithromycin $500 \mathrm{mg}$ twice daily for 7 to 14 days) is the highly recommended first-line regimen for eradication of $H$. pylori in many regions worldwide (8). Preferably, gastroenterologist admit that antibiotic therapy should be based on anti-microbial susceptibility tests but, they mostly have no other choices than empirical treatment. Clarithromycin-resistant $H$. pylori has become a problem in many regions and there is considerable interest in finding new treatment regimens that can be used without culture and sensitivity testing in diagnostic practice. Conclusively, designation of new insight for a therapeutic regimen is a priority for clinicians in close future.

2- Not only a minority (1-5\%) of population colonized with $H$. pylori develop gastroduodenal diseases, but also now we should consider even asymptomatic gastritis patients as subjects of antibiotic therapy as recent global consensus recommended $(9,10)$. It means a major shift in current therapeutic policies are necessary and we may have to think more about vaccine and other preventive choices (11).

3- H. pylori infection should be considered as a major public health and hygiene concern, therefore, scientists can justify immediate elimination of the $H$. pylori in clinical practice. In other words, we should not discuss the risks and benefits of the treatment of $H$. pylori in symptomatic or asymptomatic subjects, since the only left question would be how to treat rather than whom to treat (10).

Finally, in order to get rid of problematic reports of H. pylori colonization, clinicians' optimal goal should be complete bacterial elimination from clinical and environmental samples. For future, novel antibacterials are needed to treat the increasing problem of resistance to $H$. pylori.

\section{Conflict of interest}

Author declares no conflict of interests for this article.

\section{References}

1. Talley NJ, Zinsmeister AR, Weaver A, DiMagno EP, Carpenter HA, Perez-Perez GI, et al. Gastric adenocarcinoma and Helicobacter pylori infection. J Natl Cancer Inst 1991; 83(23):1734-9. PMID: 1770552

2. Marshall B, Warren JR. Unidentified curved bacilli in the stomach of patients with gastritis and peptic ulceration. Lancet. 1984; 323(8390):1311-5. PMID: 6145023

3. Desforges JF, Peterson WL. Helicobacter pylori and peptic ulcer disease. N Eng J Med. 1991; 324(15):1043-8. PMID: 2005942

4. NIH Consensus Conference. Helicobacter pylori in peptic ulcer disease. NIH Consensus Development Panel on Helicobacter pylori in Peptic Ulcer Disease. JAMA. 1994; 272(1):65 9. PMID: 8007082

5. Shiota S, Yamaoka Y. Strategy for the treatment of Helicobacter pylori infection. Curr Pharm Des. 2014; 20(28):4489-500. PMID: 24180402 
6. Talebi Bezmin Abadi A. Therapy of Helicobacter pylori: present medley and future prospective. Biomed Res Int. 2014; 2014: 124607. PMID: 24800203

7. Abadi AT, Kusters JG. Management of Helicobacter pylori infections. BMC Gastroenterol. 2016; 16(1):94. PMID: 27520775

8. Chey WD, Wong BC. American College of Gastroenterology guideline on the management of Helicobacter pylori infection. Am J Gastroenterol. 2007; 102(8):1808-25. PMID: 17608775
9. Lee JY, Kim N. Future trends of Helicobacter pylori eradication therapy in Korea. Korean J Gastroenterol. 2014; 63(3):158-70. PMID: 24651589

10. Talebi Bezmin Abadi A. Helicobacter pylori: Emergence of a Superbug. Front Med. 2014; 1:34. PMID: 25593908

11. Talebi Bezmin Abadi A. Vaccine against Helicobacter pylori: Inevitable approach. World J Gastroenterol. 2016; 22(11):3150-7. PMID: 27003991 